\title{
EL PROGRAMA ICONOGRÁFICO DEL PALACIO DE CAMPO REAL EN JEREZ DE LA FRONTERA. INTERPRETACIÓN Y FUENTES IMPRESAS
}

\author{
THE ICONOGRAPHIC PROGRAM OF THE CAMPO REAL PALACE IN \\ JEREZ DE LA FRONTERA. PRINTED SOURCES AND INTERPRETATION
}

Bruno Escobar Fernández

Universidad de Sevilla

https://orcid.org/0000-0003-4852-I22X

Manuel Romero Bejarano

Universidad de Sevilla

https://orcid.org/0000-0003-2433-70I4

\begin{abstract}
This study broaches the iconographic program of the Campo Real palace in Jerez de la Frontera (ca. 1535-1545). After a brief exposition of the life of Pedro de Benavente Cabeza de Vaca, who commissioned the palace, this study analyses the cultural context of the work, establishing Barthelemy Chasseneuz's book Catalogus Gloriae Mundi (1529) as the main iconographic source of the program. This discovery allows us to reconstruct its now fragmentary iconographic attributes and to posit the main keys to discover its meaning. In addition, this study proposes the Humanist Bernardino de Riberol as the conceptual author of the program, and his Libro contra la ambición (1556) as an essential source to reconstruct the meaning of the program, which has been extensively analyzed by other authors.
\end{abstract}

KEYWORDS: Campo Real Palace; Pedro de Benavente; Iconographic Program; Bernardino de Riberol.

RESUMEN • Este trabajo analiza el programa iconográfico del palacio de Campo Real de Jerez de la Frontera (ca. 1535-1545). Tras trazar un breve retrato de su comitente, Pedro de Benavente Cabeza de Vaca, abordamos el contexto cultural en que se fraguó la obra y señalamos por primera vez la fuente iconográfica empleada: el Catalogus Gloriae Mundi de Barthelemy Chasseneuz (1529). A través de este hallazgo nos aproximamos a los atributos originales -hoy fragmentarios- de la obra, y damos a conocer las claves generales de su significado. Así mismo, el humanista Bernardino de Riberol es propuesto como autor conceptual del conjunto y su Libro contra la ambición de 1556 como un recurso esencial para reconstruir el discurso del programa, al que numerosos autores se han aproximado.

PALABRAS CLAVES: Palacio de Campo Real; Pedro de Benavente; Programa iconográfico; Bernardino de Riberol. 
"Con unas medallas entre arco y arco que no les faltaba sino el alma para hablar» Cristóbal de Villalón, El Crotalón

La casa de Pedro de Benavente Cabeza de Vaca [fig. 1], conocida actualmente como palacio de Campo Real por el marquesado que ostentaron sus descendientes, es una de las más tempranas muestras civiles de arquitectura renacentista en Jerez de la Frontera y su entorno. ${ }^{1}$ Resultado de la prosperidad que la ciudad disfrutaba hacia el cambio de los siglos XV y XVI (Ruiz, 2020), Jerez se alzó como motor artístico de su zona, en pleno proceso de efervescencia constructiva, especialmente religiosa desde finales del XIV, y con un discreto pero creciente interés por la renovación artística a la romana desde principios de la centuria del XVI (Romero, 2009: 77-93). Numerosos mercaderes, tanto peninsulares como extranjeros, llegaron a la ciudad y sus alrededores desde finales del XV (Mingorance, 2014), y entre ellos Pere Benavent, cuyos descendientes pronto pasarían a vivir en Jerez. ${ }^{2}$ Mercader de profesión, aunque formado como caballero, Benavent tomó parte en la conquista de la Palma, obteniendo en pago diversas preseas que influyeron en el curso de su vida y la de sus descendientes. Destacaba sobre ellas un ingenio de azúcar en el municipio palmero de Los Sauces (Viña, 2003: 323-336).

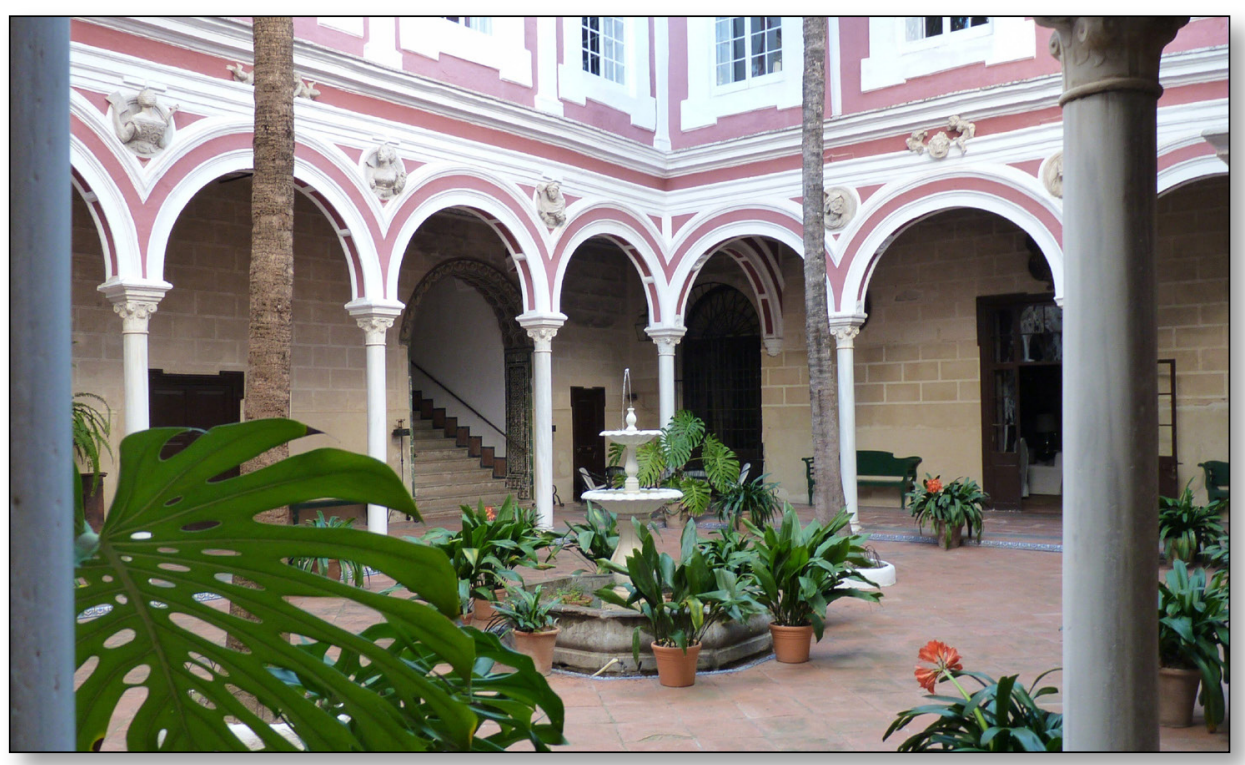

Fig. 1. Patio principal del palacio de Campo Real. Juan Pérez y Diego Pérez, ca. 1540-1545.

1. Las primeras muestras del Renacimiento en la zona de Jerez, y buena parte de la actual provincia de Cádiz, se dan en la Cartuja de Santa María de la Defensión cuya portada del refectorio, datada en 1536 (Mayo, 2001 : 87) puede ser considerada la primera muestra de arquitectura renaciente en el entorno. Al poco surgieron otros brotes del nuevo estilo en diferentes casas señoriales de la ciudad, en especial en el Palacio de los Ponce de León, y pronto en la morada de Benavente (Romero, 2014).

2. Hay indicios que hacen sospechar que primero se instaló en Sevilla. Benavent casó con la sevillana Marina de Carvajal, y sabemos que esta nunca se trasladó a Cádiz, residiendo hasta su muerte en la Calle Abades de la ciudad hispalense. Archivo Histórico Nacional de Madrid (AHN Madrid), Consejo de Órdenes, Caballeros de Santiago, Expediente 969, Fol. 17 vto. 
Su hijo, Pedro de Benavente Cabeza de Vaca, nació en Sevilla hacia 1498, aunque pronto se instaló en Cádiz, donde residía por entonces su padre. Allí participó activamente en la defensa de la ciudad, frenando los continuos ataques musulmanes (Sancho, 1953). Siguió el sendero paterno en la dedicación comerciante y, de hecho, la principal fuente de sus riquezas fueron los negocios que mantenía entre la bahía de Cádiz y Canarias (Mingorance, 2017: 99). Antes de 1530, Benavente ya estaba radicado en Jerez, donde contrajo matrimonio con Beatriz Bernalte Dávila y Virués, logrando luego que sus descendientes entroncaran con importantes linajes jerezanos (Abellán, 2012: 105-106). Desde ese momento, Pedro de Benavente buscó despojarse de la faceta mercaderil de su padre para vestirse con las ropas del patriciado urbano y forjar un linaje de nobleza. Así, cuando sus implicaciones bélicas fructificaron, pudo sumar a la veinticuatría que le había comprado su padre en el Cabildo jerezano cuando aún era menor de edad, otros cargos como el de regidor de Cádiz o comendador vitalicio de Jerez (Mingorance, 2017: 102-103). Como vemos, en su cursus honorum las armas jugaron un destacado papel, pero el dinero no fue menos importante. De hecho, el epistolario conservado de Benavente revela cómo cohechó a no pocas figuras relevantes de su tiempo para procurarse, entre otras distinciones, el hábito de Caballero de Santiago (que le fue dado en 1530) o el corregimiento de Málaga que, sin embargo, no llegó a obtener. ${ }^{3}$

A pesar de lo logrado, la figura de Benavente desataba profundas enemistades entre la nobleza jerezana, que no perdonó nunca sus orígenes (Sancho, 1953). Una familia de mercaderes aparecida en la zona al filo del quinientos era una advenediza a ojos de la aristocracia local, que había ganado su nobleza guerreando en la frontera desde los tiempos de la reconquista (Sánchez Saus, 1996). En este sentido, el presente trabajo propone la hipótesis de que la postura de Benavente frente a sus detractores fue emprender una campaña de propaganda e imagen pública. En su empeño por forjar un linaje, el mecenazgo artístico se postuló como un arma biopolítica para la consecución de sus intereses y de reafirmación nobiliaria. Y es que, allá por la década de 1530, restaba a Pedro de Benavente una residencia acorde con sus pretensiones; un escenario donde exhibirse, a imitación de la nobleza bajoandaluza que por entonces estaba levantando o remozando suntuosas residencias, haciendo uso de la arquitectura renaciente, y demostrando así su magnificencia (Lleó, 2012: 39).

El impacto que causó reforma de la casa de Pilatos en la arquitectura de Sevilla, especialmente a partir 1530 (Lleó, 2017: 74), tuvo su repercusión también en Jerez. Un cambio en los atributos palaciegos se detecta en los mismos años, en especial a raíz de la obra del palacio de los Ponce de León, que debió concluir hacia 1537 (Romero, 2016: 162). Comenzaron a edificarse residencias en las que el nuevo estilo a la romana adquiría una dimensión emblemática, centrada en muchas ocasiones en el empleo de columnas marmóreas en los patios, mientras la mayor parte de la fábrica seguía siendo gótica (Marías, 1989: 261). ${ }^{4}$ Benavente bebió de esa corriente renovadora, pero se alzó sobre estas experiencias al dotar a su morada de un grado de sofisticación inédito en la ciudad. La obra, que comportaba el remoce de una casa de origen islámico, debió iniciarse en la primera mitad de la década de 1530, para estar concluida en su mayor parte hacia 1545. La documentación ofrece el nombre de los

3. Se conservan en el Palacio de Campo Real, en el Archivo de Manuel Domecq Zurita, Jerez, legajo 31 . Un trabajo nuestro, en preparación, analiza en profundidad este asunto. Hasta su publicación, véase Sancho (1925). 4. Los patios habían concitado buena parte de las primeras intervenciones privadas en el nuevo lenguaje. Además de Pilatos o el Alcázar de Sevilla en su patio de doncellas especialmente (Marín, 1990: 127-179), es también el caso de otros palacios y castillos españoles, desde el valenciano Vich, a La Calahorra o Vélez-Blanco (Marías, 1989: 260). 
artífices: Juan Pérez y su hijo Diego (Romero, 2014: 71-82). Además de ejecutar la reforma a la romana exclusivamente, sin usar la tradición gótica, se dotó de un importante papel a las inclinaciones humanísticas de Benavente. Se configuró un programa iconográfico mediante medallones alegóricos que se dispusieron en el patio de la casa. El espacio elegido, siendo ya importante por sus valores de representación a ojos del común, una vez hermoseado con los relieves constituyó todo un canto a la liberalidad y la humanitas del comitente. De esta manera, la morada de Pedro de Benavente se convertía en el lugar representativo de su poder político en el plano urbano. Un espacio en el que confluían arquitectura e intelectualidad, magnificencia y liberalidad: un jalón más en un programa de vida que vio en el arte un valor personal para el ascenso social, reafirmación y la perpetuación del linaje. ${ }^{5}$

Si bien no pocos autores se han aproximado al mensaje del patio, ${ }^{6}$ es el análisis de las relaciones de Pedro de Benavente con la intelectualidad de su tiempo y su pretensión de estatus social nuevo lo que nos abre la puerta para acometer una lectura global del mensaje soportado por los relieves del patio y no caer en excesos iconológicos (Marías, 1989: 29).

La relación del comendador con los círculos intelectuales de su tiempo ha sido señalada especialmente por Moreno (2017a: 171). Aun así, su contexto cultural sigue estado poco definido, pues son referencias tangenciales en su mayoría las que lo vinculan al ambiente humanista. Se ha resaltado en este sentido al ahijado de Benavente: Juan de Barahona y Padilla. Su labor humanística como traductor de Piccolomini al español, así como su actividad como poética y anticuaria, ha sido estudiada y puesta de manifiesto por Cuevas (1964) y Moreno (2017a: 170-181). Conocemos también su cercanía con Fray Francisco de la Barca Maldonado, doctor en Teología, figura aún muy desdibujada que ostentó importantes cargos en la Orden de Predicadores. Esto podría dejar translucir la relación del comitente con el monasterio de Santo Domingo de Jerez, importante hervidero cultural de su tiempo. ${ }^{7}$ Podemos añadir que en 1541 fue nombrado comisionado del Cabildo para la creación del colegio de Santa Cruz en la ciudad, por iniciativa de san Juan de Ávila. Este nombramiento no parece casual en vista del poder económico del comendador y quizás por su interés en el mismo (Sancho, 1959: 28). Desde la publicación de su testamento (Mingorance, 2017: 127-129), se ha sugerido la relación de Benavente con cierta corriente de corte erasmista en la ciudad (Moreno 2017a: 171 y 2019: 119-120). El principal indicio de esto son algunas de sus mandas testamentarias, en especial la petición de que su cadáver fuera puesto durante sus exequias "en tierra, de donde fue criado, y no en cama alta ni con más pompa»; que llevaran su cuerpo hasta el templo seis vecinos de su collación, los más pobres que se hubiera; o que nadie llevara luto por él. ${ }^{8}$ La negación del luto se ha documentado en otros vecinos de Jerez contemporáneos a Benavente (Moreno, 2019: 119-120), y fuera de la ciudad, como en las mandas testamentarias de don Fadrique Enríquez de Ribera, quien poseía los Coloquios de Erasmo en su biblioteca personal (Lleó, 2017: 68).

Con independencia de la interpretación que hagamos de las disposiciones de su testamento, no todo lo concluyentes que deseamos, su vinculación al erasmismo es irrefutable

\footnotetext{
5. Quizás sea el linaje genovés de los Pinelo, comerciantes de enorme riqueza que alcanzaron importantes cargos y trazaron vínculos con la nobleza sevillana, el que guarde mayor relación (salvando las distancias) con el programa vital de Benavente. La casa de los Pinelo es ejemplo parlante de esto (Lleó, 2012: 52).

6. Esteve (1933: 204), Ríos (1991: 52-66); López (1992) y (1995: 156-65); Ríos (1999: 60); Aguayo (2002, 7-26) y Moreno Arana (2019: 120-121).

7. Bernardino de Riberol, de quien se hablará a continuación, ya señaló en 1556 la relación de Benavente con la Orden Dominica en un asunto relacionado con la compra de su veinticuatría en Jerez. (Riberol, 2006: 56).

8. Archivo de Protocolos Notariales de Jerez de la Frontera, Oficio XVIII, Simón García Copín, Fol. 463 r y ss., 14 de septiembre de 1556.
} 
atendiendo a otro hecho: su mecenazgo sobre la publicación, en 1556, del Libro contra la ambición y codicia desordenada de este tiempo, llamado alabanza de la pobreza, del humanista canario Bernardino de Riberol. La paternidad de Erasmo sobre las ideas vertebradoras de la obra es insoslayable, y ha sido extensamente estudiada en Riberol (2006) y Hernández (2013). El libro está dirigido a "al muy magnífico señor Pedro Benavente Cabeza de Vaca», y su blasón hermosea la edición en los ornamentos tipográficos (Riberol, 2006: 51-57) [fig. 2].

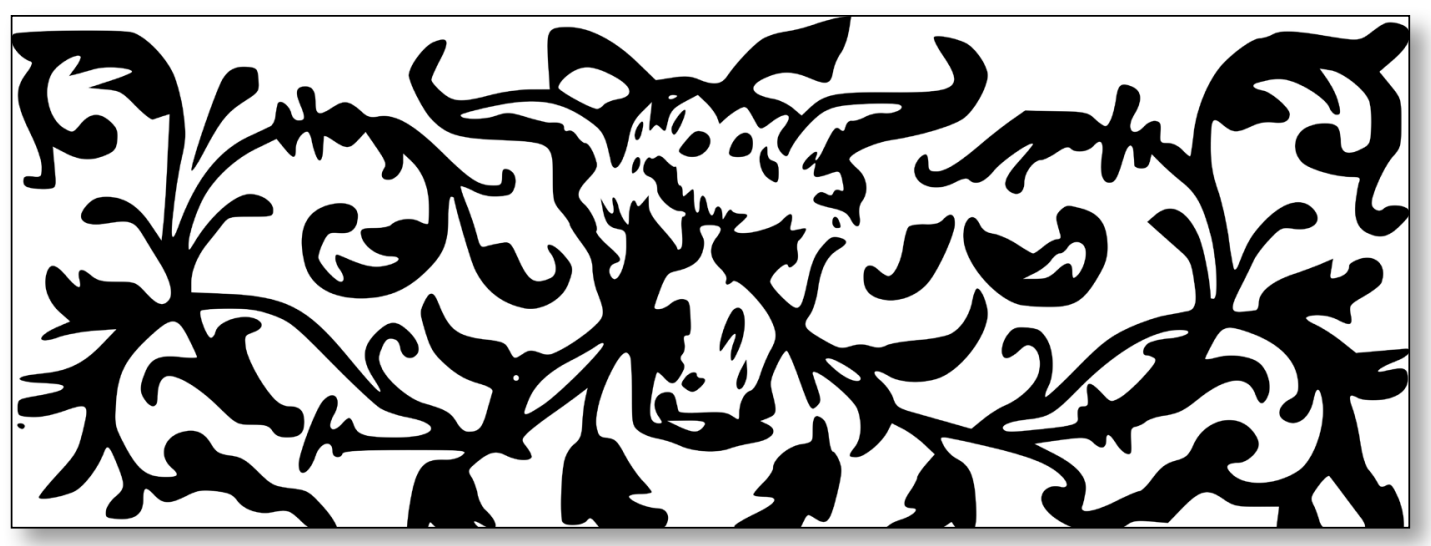

Fig. 2. Ornamento tipográfico a partir del blasón de Pedro de Benavente en el Libro contra la ambición de Bernardino de Riberol (Sevilla, Martín de Montesdoca, 1556).

Nacido en 1509 en Gran Canaria, Bernardino de Riberol era familiar lejano de Benavente. Cursó estudios de Derecho en Sevilla, que concluyó poco después de 1530. Allí debió entrar en contacto con el erasmismo tan difundido en la ciudad hispalense (Bataillon, 1966: 545). Tras completar su formación, Riberol marchó a La Palma para ejercer desde ca. 1540 como letrado del cabildo. Su única obra publicada en vida fue el ya mencionado Libro contra la ambición. En el elogio que dedica Riberol a Benavente en la Epístola introductoria del mismo, señala al comendador como ejemplo de la «pobreza espiritual» que motiva la redacción del texto, idea que a su vez bebe de Erasmo (Riberol, 2006: 11-48). Parece evidente que los mendigos y la ausencia de catafalco en sus exequias son correlatos de las ideas del autor canario. Y no era contradictorio hablar de pobreza y censurar la ambición mientras se aludía a un hombre tan rico como Benavente, pues "yo tengo a vuestra merced por pobre de espíritu y como tal lo dedico, porque he visto y conozco del que posee lo que tiene con humildad, sin levantarse ni ensoberbecerse con ello, y que lo reparte liberalmente» (Riberol, 2006: 56). Una relación entre autor y mecenas como esta no fue infrecuente; otros hombres poderosos del mismo tiempo protegieron a erasmistas bajo su amparo, auspiciando así la difusión de este pensamiento con un evidente beneficio mutuo (Pons, 2003: 269-294).

Mas podemos buscar una función a la obra del autor canario. La licencia para su impresión se fecha a seis de julio de 1556, dos meses antes de la redacción del testamento del comendador. Si Benavente tuvo en sus manos la obra impresa, fue in articulo mortis, y los beneficios o consecuencias, póstumos. Parece que la muerte le sobrevino rápidamente, y el texto acabó por convertirse en una especie de ideario, un testamento espiritual que suscribía el comendador y que venía a suplir la ausencia de una sepultura y capilla propia, que tardaría décadas en encargar su hijo (Sancho: 1947). Se ha documentado la ausencia de Riberol entre octubre de 1555 y enero de 1556 de su oficio en el Cabildo de la Palma (Riberol, 2006: 31-32), posiblemente, el momento en que se gestaría la publicación del libro, a buen

IMAGO, NÚM. 13, 2021, 67-84 
seguro con alguna visita a Jerez de por medio, donde se perfilaran los detalles. Sin embargo, las relaciones que se pueden trazar entre el programa iconográfico del palacio de Campo Real y el texto de Riberol son suficientemente claras como para sospechar que las ideas que estructuran el libro ya las había formulado el autor hacia 1540, y que probablemente el Libro contra la ambición existía en sus primeros estadios en dicho punto.

Con esto queremos distanciarnos del hasta ahora señalado como probable autor del programa iconográfico del patio: Fray Francisco de la Barca (Moreno, 2019: 121), y señalar a Bernardino de Riberol como su autor. Previamente debemos recalcar que ya se ha atribuido al humanista canario la autoría de otro programa iconográfico: el de la fachada del Cabildo de Santa Cruz de la Palma (Martín, 1995: 159), con lo que, de ser cierta nuestra hipótesis, ambas atribuciones podrían verse refrendadas. Al no conocerse ningún escrito que abordara el significado de esta obra, su Libro contra la ambición es la única guía que puede contribuir al desentrañamiento del mensaje, de ahí su importancia para este estudio.

Pese a que los descendientes de Pedro de Benavente prácticamente nunca han abandonado el palacio y esto ha contribuido a su conservación en líneas generales, según la tradición, el patio sufrió los efectos de un ataque popular durante la ocupación francesa, lo que explicaría el deterioro arbitrario de los medallones alegóricos (Escobar, 2020: 76). ${ }^{9}$ Esto ha lastrado la mayoría de las interpretaciones sobre el mensaje, que hemos citado anteriormente, y de las que nos distanciamos. El único modo de reconstruir los atributos originales es acudir a la fuente iconográfica de la que beben, desconocida hasta la fecha y que publicamos aquí por vez primera.

La fuente icónica principal que se empleó fue una xilografía procedente del libro Catalogus Gloriae Mundi de Barthelemy de Chasseneuz (1529: Parte X, Fol. 2) en su edición príncipe (Lyon, 1529) [fig. 3]. La mayor parte de las medias figuras femeninas de los medallones están inspirados en dicha estampa dedicada a las artes mayores y menores, así como a otras disciplinas del saber. Mediante la idea programática de los caminos que llevan a la gloria, el Catalogus desgrana los conocimientos del mundo con afán enciclopédico, desde la guerra a las artes y las ciencias. Si bien está ampliamente documentado el uso de las Illustrium Imagines de Andrea Fulvio o el Imperatorum Romanorum Libellus de Johann Huttich, como fuentes para esa moda de la ornamentación con medallones tan típica -como ocurre en la Casa de Pilatos (Lleó, 2017: 71)-, el uso del Catalogus es inédito como fuente de estas características en nuestro Renacimiento. Nuestro hallazgo se debe poner en relación con la aportación de Moreno (2017b: 21 1-214), que ha señalado las Imagines de Fulvio como fuente icónica para el Palacio de Riquelme jerezano, unos años posterior. Estamos pues ante dos fuentes librarias que bien podrían abrir un camino para el desentrañamiento riguroso de otros programas simbólicos en la arquitectura jerezana del quinientos.

El programa iconográfico se estructura mediante un total de catorce medallones: diez con figuras femeninas portadoras de atributos, dos personajes mitológicos identificados con una inscripción y otros dos correspondientes a retratos idealizados de Benavente y su esposa.

Siguiendo el recorrido natural de entrada al patio (esto es, por la panda occidental), el primer medallón, muy dañado, muestra a una figura que casi ha perdido sus atributos, salvo un resquicio en la moldura que la enmarca: son flores. Se trata de la Dialéctica, y sigue el tipo iconográfico del Catalogus [fig. 4]. Las flores salían de la trompeta que portaba originalmente en su mano izquierda. En la diestra, sumamente dañado, aún se distingue el comienzo de un

9. El desigual estado de conservación de los medallones, unos destrozados y otros intactos, apunta a un daño intencionado. Si no fue la turbamulta enfurecida, bien pudo ser la tonelería que a mediados del XIX ocupó parte de la casa (Parada, 1875: 72). 


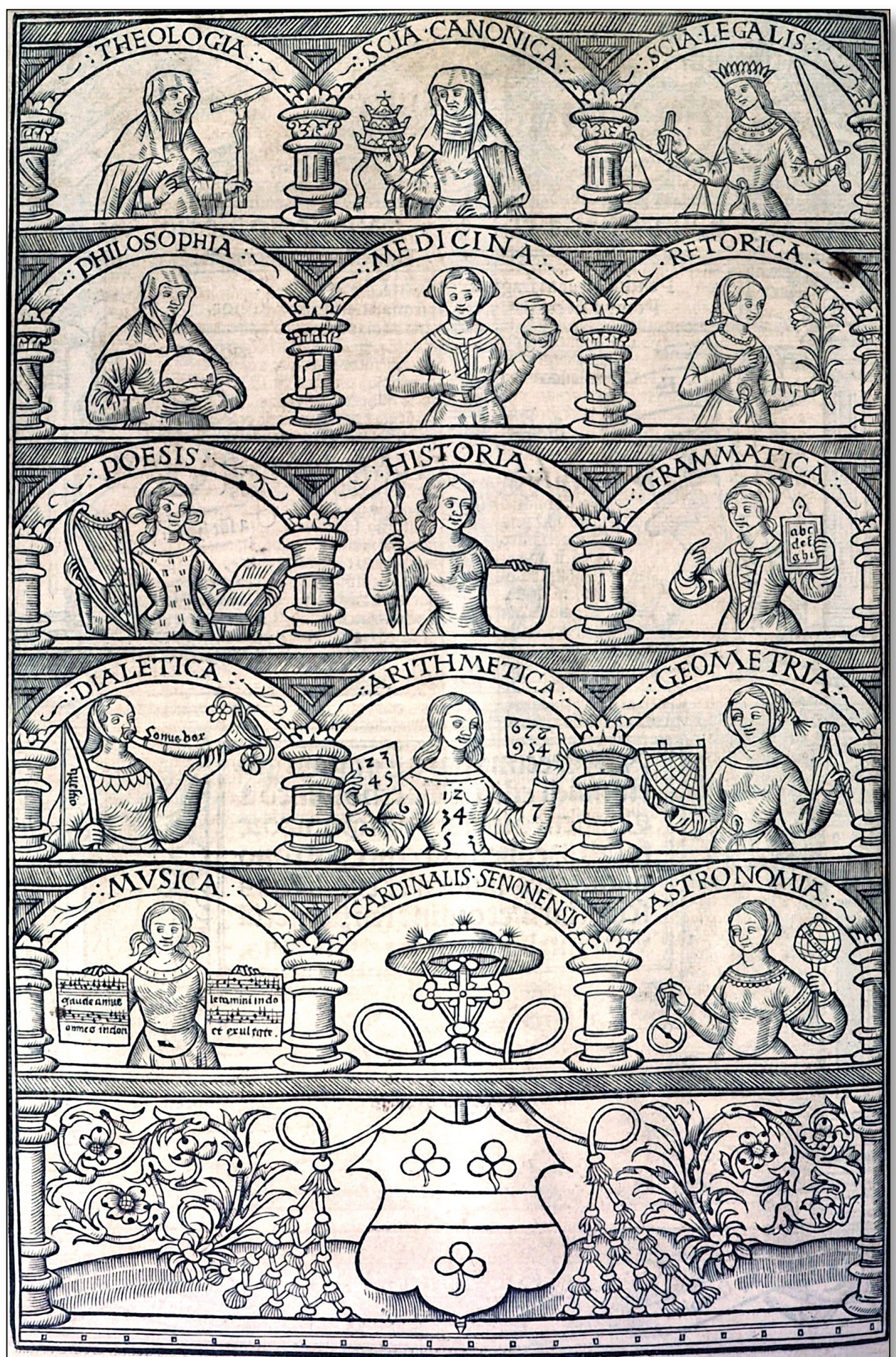

Fig. 3. Xilografía del Catalogus Gloriae Mundi de Barthelemy de Chasseneuz (Lion, Dionysium de Harsy, 1529).

IMAGO, NÚM. I3, 202I, 67-84 


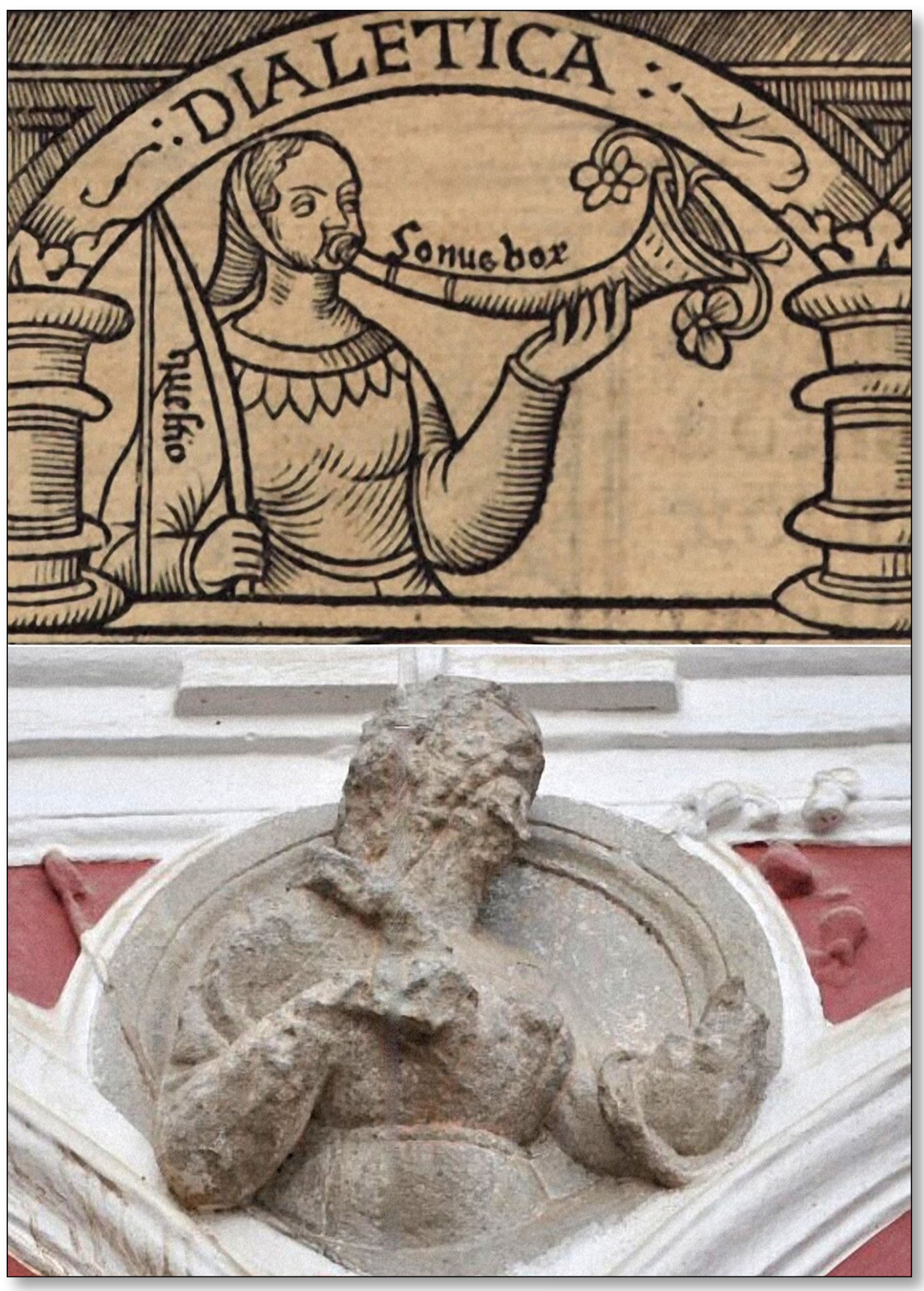

Fig. 4. Comparativa entre la Dialectica y su medallón correspondiente. 
arco. Además, se ha añadido (pues no aparece en la fuente grabada) una flecha o un arpón a la espalda, acorde con otras representaciones de la época (Iglesia, 2001: 144).

El segundo es el único de los medallones que se repite, tanto en la panda occidental como en la oriental [fig. 5]. Se corresponde con la representación de la música en la fuente impresa, aunque como veremos, no quiere ser ese su significado. Porta en la izquierda una partitura y en la derecha una flauta. La partitura de una de las dos figuras tiene notación musical interpretable, en sistema de chiavette, extraída de una obra polifónica vocal (probablemente la voz de alto, lo que queda de manifiesto por la clave de do en segunda empleada). ${ }^{10}$ Hasta el momento no se ha podido identificar a qué pieza musical pertenece el fragmento, y si guarda o no relación con el programa. Que se encuentre de espaldas, como en un acto teatral, es parte del mensaje. López Campuzano (1995: 61) atinó al identificarlas como la adulación o la lisonja, ya que la música, y en especial los instrumentos de viento, guardan estrecha relación con ambos conceptos (López-Peláez, 2004: 81-96). Aquí entra en juego el pensamiento de Riberol, quien conocía sobradamente el Del menosprecio del mundo de Erasmo. Ahí se dice que el viento es «símbolo justo del pestífero lenguaje de los aduladores y de los maledicentes. Poco importa el lado de que soplan, y por ello siempre son de temer" (Riberol, 2006: 172). Igualmente esclarecedoras son las posteriores palabras de Saavedra Fajardo, al recoger lo que la tradición decía de los acostumbrados a la lisonja: «Están muy hechas sus orejas a la armonía de la música, y no pueden sufrir la disonancia de las calamidades que amenazan. De aquí nace el escoger predicadores y confesores que les digan lo que desean, no lo que Dios les dicta» (1655: 353). Esta alegoría, subrayada por partida doble al repetirse a uno y otro lado del patio, puede vincularse a la visión de la corte que predominaba en tiempo de Carlos V: «lugar del engaño, la sofisticación y la alienación del individuo» (Checa, 1987: 12). Se trata, pues, de una advertencia para dar la espalda a la lisonja.

La Geometría ocupa el tercer medallón [fig. 6]. Ha perdido sus atributos parlantes; tan solo queda una de las patas del compás que sostiene con la mano derecha. Gracias al grabado de la obra de Chasseneuz, vemos la minuciosidad con que fue copiado: ni el gracioso lazo del cinturón con que se ciñe el vestido se le escapa al escultor. Gracias a este sabemos que en la otra mano sostuvo un cuadrante, antiguo útil empleado para la medición de la altura de los astros durante la navegación.

El cuarto plantea mayores problemas de identificación, pues no se tomó del Catalogus [fig. 7]. Vemos a una mujer con un gorro de tela mirando un libro y sosteniendo un instrumento de mango elongado y remate circular. El deterioro de este conjunto ha provocado la pérdida del remate, que estaría encastrado usando los orificios que se hoy ven, y muy probablemente realizado en metal, jugando con las cualidades reflectantes de este material. Aunque López Campuzano (1995: 59-60) lo identifica como un cetro, en alusión a la autoridad, lo cierto es que bien puede interpretarse como un espejo, elemento fuertemente asociado a la prudencia y que frecuentemente aparece en compañía de un libro (Montesinos, 2019: 290). De este modo, el medallón podría leerse como una llamada al gobernante a mirarse en el espejo de esta virtud, aludiendo con el libro a la necesidad de instruirse en ejemplos de prudencia. Así, en contraposición al medallón antecedente, que advierte sobre la lisonja y adulación de las personas cercanas, este sería una alegoría visual tocante a la reflexión interior y la instrucción como fuente de prudencia (Montesinos, 2019: 190). La importancia que da Riberol a esta virtud en su pensamiento (2006: 63) queda patente en el patio, pues volverá a aparecer la prudencia en compañía de la templanza, como luego se abordará. 


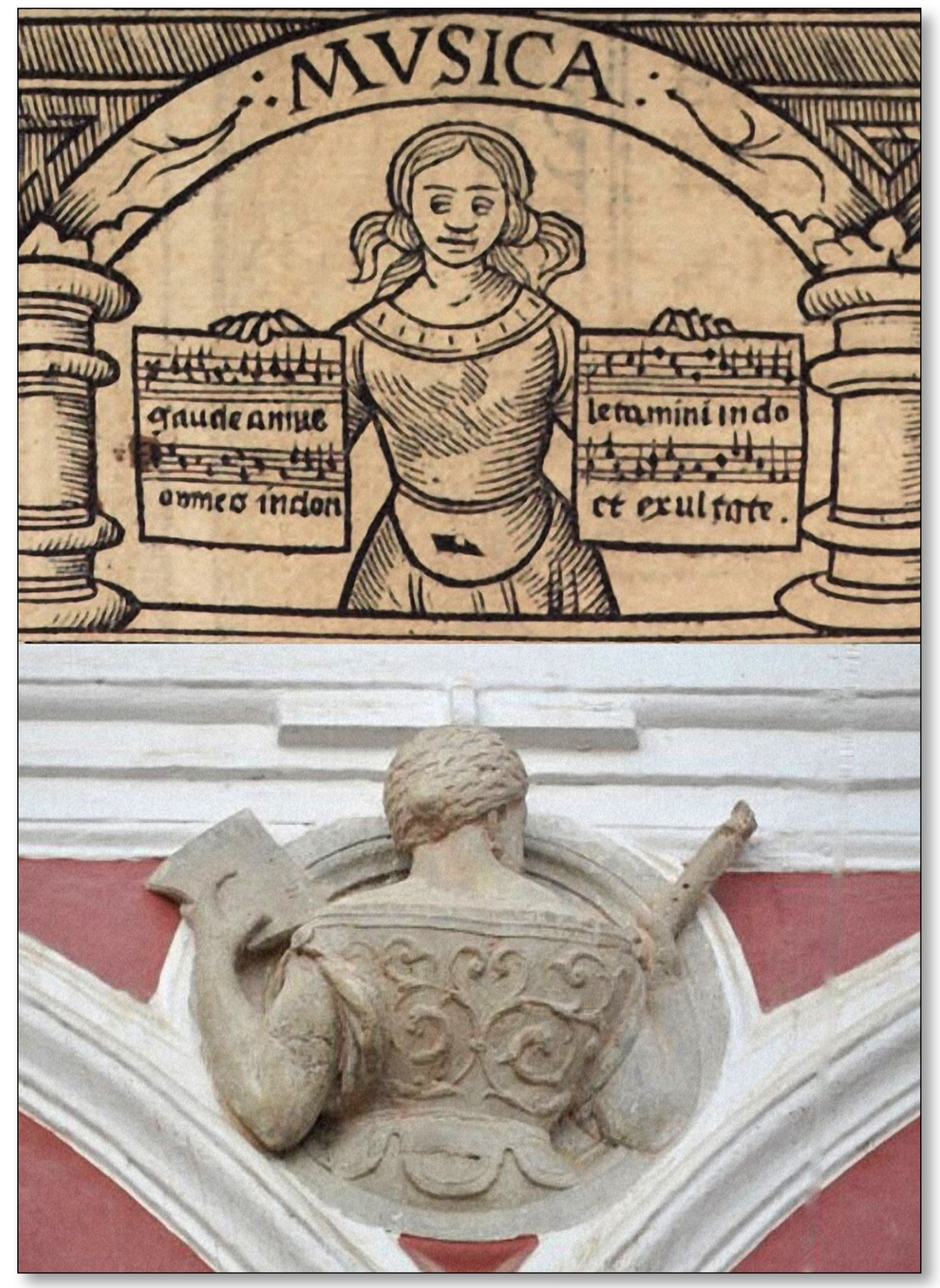

Fig. 5. Comparativa entre la Música y el medallón de la Adulación o la lisonja. 


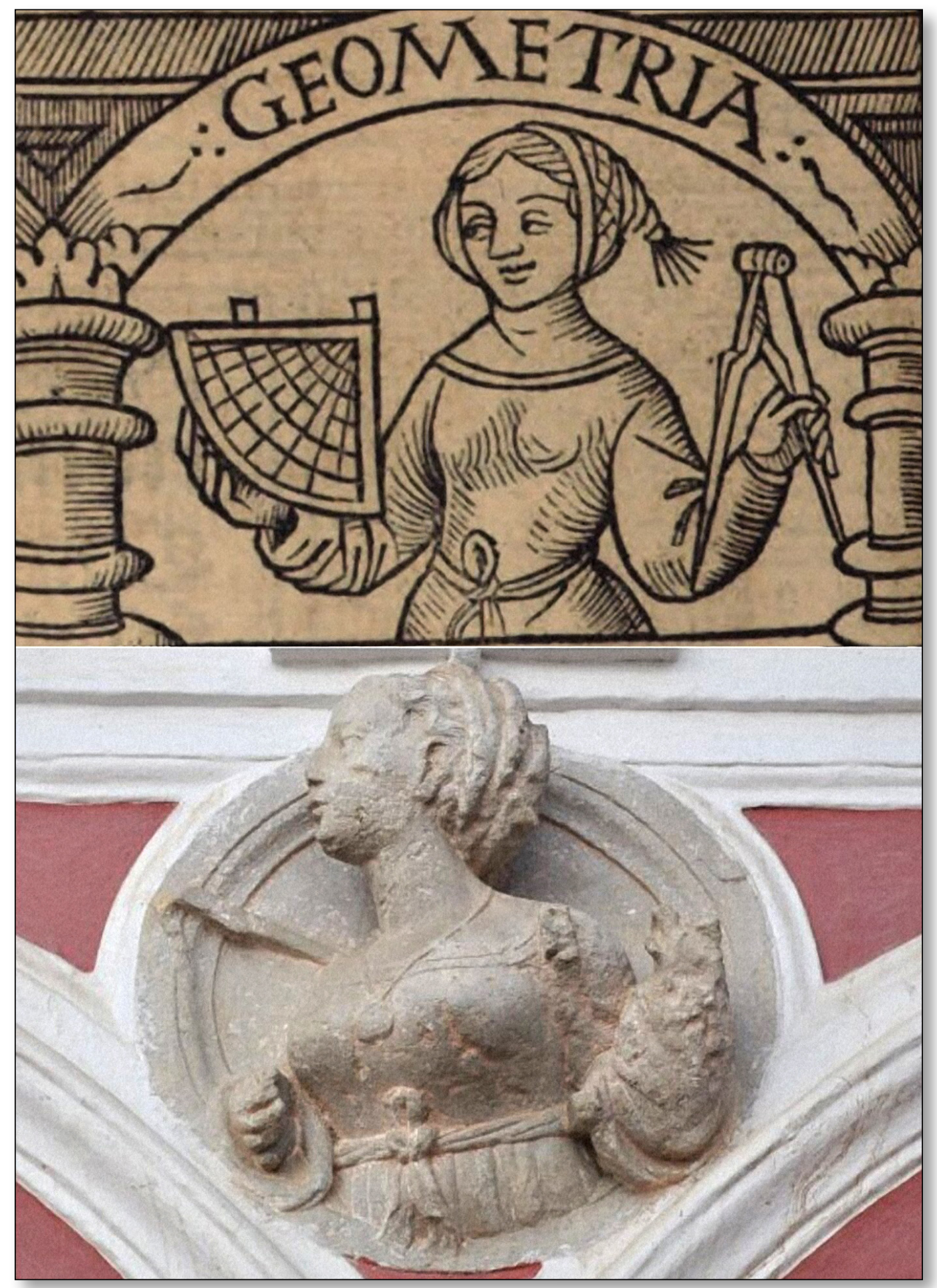

Fig. 6. La Geometría: comparación entre la fuente impresa y el medallón.

IMAGO, NÚM. 13, 2021, 67-84 


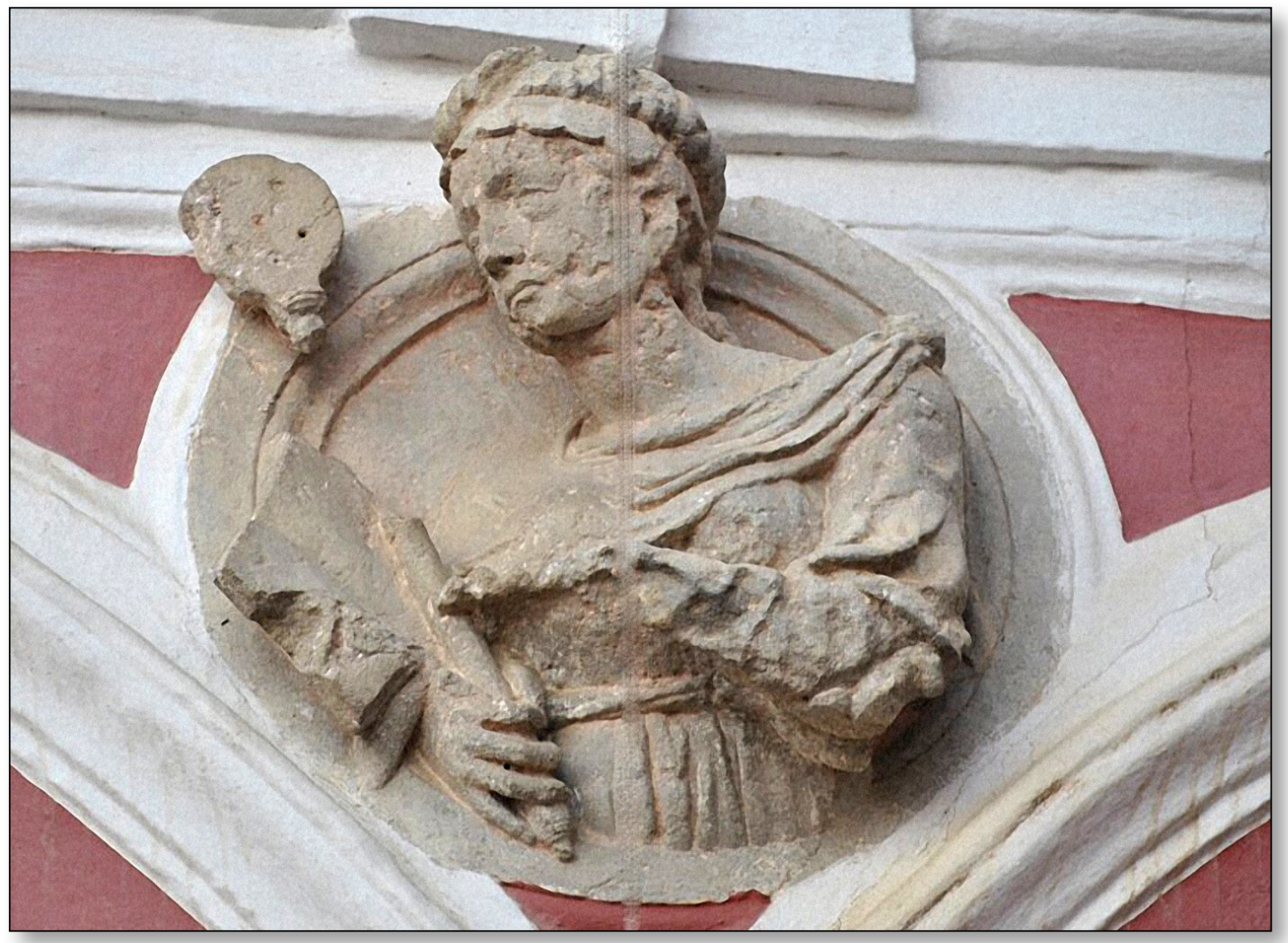

Fig. 7. Medallón del Gobernante prudente.

Presiden el patio dos tondos con los retratos alegóricos de los comitentes y sus correlatos en la planta superior. Abajo aparece el busto de Pedro de Benavente, ataviado con una toga y una borgoñota. Este atuendo, muy cercano al de un héroe bélico, parece una clara alusión a sus triunfos militares. Y el de Beatriz Bernalte, velada, al modo de las matronas romanas [fig. 8]. En el piso superior, Eneas luce yelmo y armadura, mientras que Dido viste a la moda y porta una corona sobre su larga cabellera suelta. Hay que tener en cuenta que el segundo piso quedó inconcluso en el XVI, siendo esta panda la única que se levantó. Quizás los restantes vinieran a completar una galería de enamorados de la Antigüedad, lo que explicaría la elección de Eneas como primer representado, pues era hijo de Venus. Tal y como indica Checa (2006: 197), esto no fue raro en el Renacimiento hispano, y así lo recoge El Crotalón de Cristóbal de Villalón. Al describir un patio áulico se detallan las «medallas entre arco y arco que no les faltaba sino el alma para hablar. Eran las imagines de Piramo y Tisbe, de Philis y Demophon, de Cleopatra y Marco Antonio, y ansí todas las demás de los enamorados de la antigüedad" (Villalón, 1982: 168-169).

Continuando con los medallones alegóricos, el quinto responde al derecho (o Scientia Legalis, como aparece en el Catalogus), y presenta la conformación icónica clásica de la Justicia: una balanza, en alusión a la equidad, y una espada, por la fuerza ejecutiva. De ambos objetos los restos son escasos en el medallón, aunque no cabe duda de la identificación. 


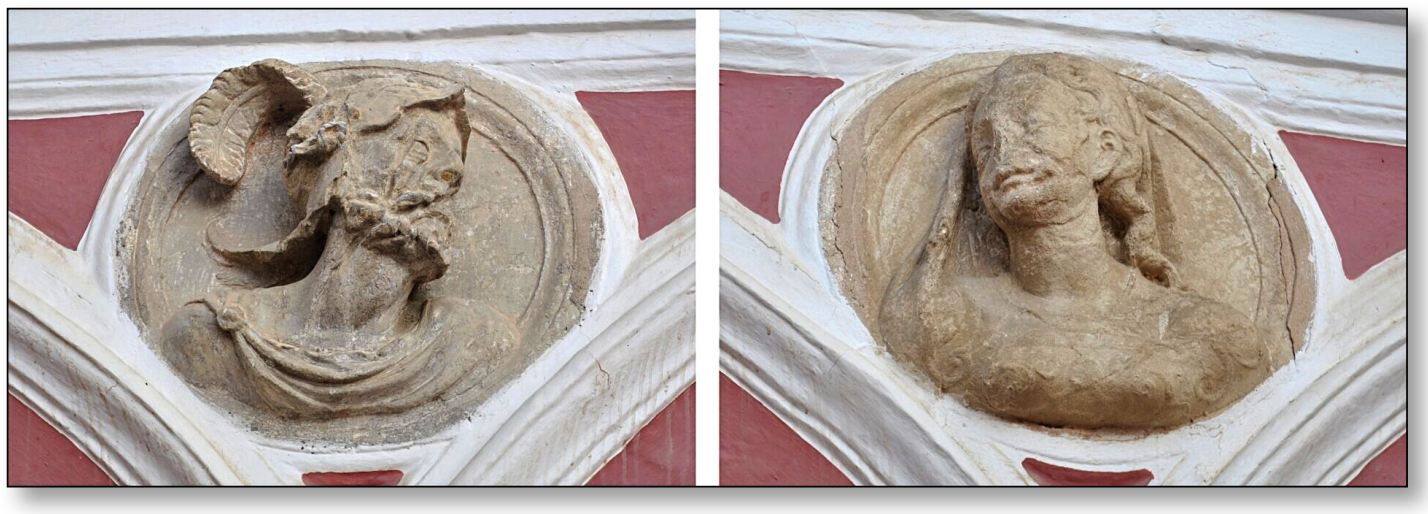

Fig. 8. Retratos idealizados de Pedro de Benavente y su esposa, Beatriz Bernalte.

Otro tanto sucede con la Gramática, protagonista del siguiente, cuyos atributos están perdidos por completo, pero que a raíz del grabado se ve que señalaba con la mano derecha una tablilla escrita que sostenía con la izquierda [fig. 9].

Tras la repetición del medallón de la lisonja, el siguiente es el más acorde a la fuente de Chasseneuz, y se ubica en el extremo de la panda oriental. En él podemos ver a una mujer velada que sostiene una cruz en su mano izquierda, representado a la Teología [fig. 10].

Por último, enfrentados diametralmente a los retratos idealizados del matrimonio, encontramos a la Prudencia y la Templanza. Ambas virtudes cardinales se han representado con sus habituales atributos, esto es, el espejo y la serpiente en la prudencia, y las jarras de agua en la templanza. La única concesión original aquí presente es el leonté que viste en su cabeza la segunda. No parece casual que Riberol ponga a Hércules como ejemplo de la templanza en los antiguos en la Epístola a Benavente de su libro (2006: 52), con lo que adquiere carácter de parangón.

El mensaje general del conjunto debe leerse como una laudatio del caballero Pedro de Benavente mediante la exaltación de las virtudes y ciencias que detentaba. Para ello se emplea un repertorio de conocimientos íntimamente ligados a su labor política: Derecho, Dialéctica y Gramática, como saberes apropiados del buen gobernante y el político. A esto se añade la Geometría, especialmente orientada a la navegación (de ahí el cuadrante y el compás), necesaria para quien tiene tan estrecho vínculo con Canarias; poseedor de un navío, llamado Sancti Spiritus e implicado activamente en la defensa de plazas marítimas como Cádiz. Se cierra el elenco de saberes con la Teología, propia en un caballero cristiano, cuyas inquietudes piadosas se reflejan en su testamento de manera detallada. A esto hay que añadir las advertencias doctrinales hacia la adulación y la lisonja, condenadas por la templanza y doblemente por la prudencia. Estas últimas se alzan como virtudes ejemplarizantes, enseñas de la pobreza espiritual y guías del buen gobierno, no solo político, sino también espiritual de Benavente. De ahí su posición en correspondencia con los retratos del matrimonio.

El programa entronca de manera directa con el pensamiento de Riberol, y el mensaje es, a grandes rasgos, similar al que se ha dado a la otra supuesta creación emblemática del humanista canario, el cabildo de Santa Cruz de la Palma: la exaltación de la virtud y la condena de los vicios (Martin, 1995: 159). Mensajes de esta índole, aludiendo a la conducta ejemplar y virtuosa del propietario son frecuentes en el arte español del XVI (Marías, 1989: 567-568). La aparición de los enamorados de la antigüedad, sin que podamos afinar su misión aquí 




Fig. 9. Comparativa entre la Gramática en Chasseneuz, y el medallón correspondiente. 


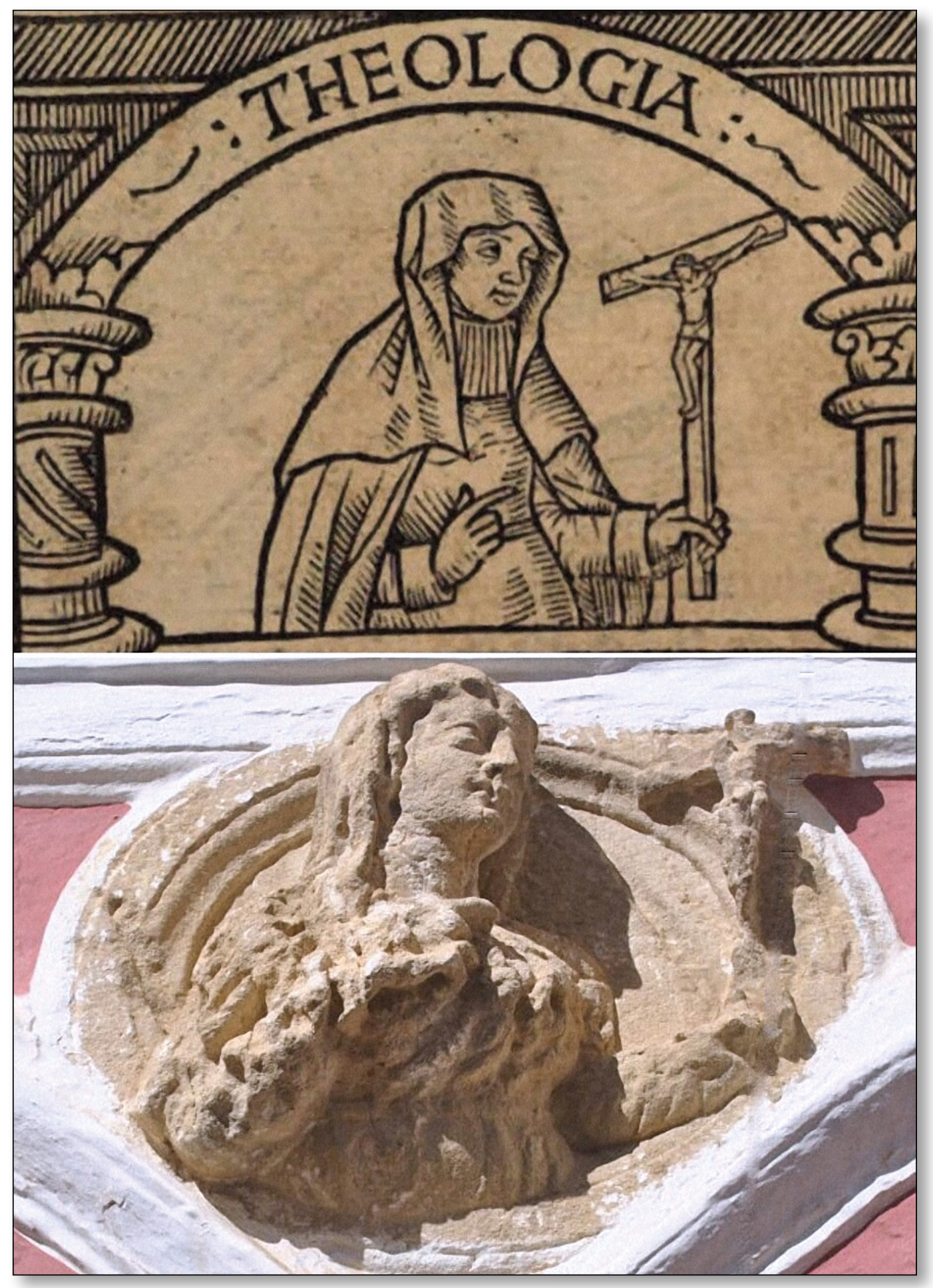

Fig. 10. Comparativa entre la Teología, xilografía y medallón correspondiente.

IMAGO, NÚM. 13, 2021, 67-84 
por lo inconcluso de esa parte de la obra, parece completar la exaltación de Benavente como grandilocuente alusión a una genealogía emblemática de enamorados, en la que se enmarca el propio matrimonio del comitente. ${ }^{11}$

Así con todo, el programa iconográfico de Campo Real se perfila como testigo preclaro de la intelectualidad jerezana del XVI y como referente trascendente para otras edificaciones de la ciudad. La puesta en valor del Catalogus de Chasseneuz y del Libro contra la ambición de Bernardino de Riberol como respectivas fuentes librarias de la obra abre nuevos caminos para la investigación. Esperamos que este trabajo incentive nuevas aportaciones en torno a la figura de Riberol, pues queda de manifiesto su -hasta ahora solo intuida- dedicación ideando programas iconográficos. La existencia de una corriente erasmista que se ha apuntado como parte de la realidad intelectual del quinientos jerezano cobra también fuerza. Todo esto abre nuevas vías de investigación en el panorama tanto literario como artístico al sur de la península. Solo nos queda esperar que futuros trabajos puedan seguir ahondando en estos asuntos y restañando con nuevos hallazgos una realidad que poco a poco parece ir perfilándose.

\section{BIBLIOGRAFÍA}

Abellán Pérez, J. [2012]. El libro del Alcázar, Jerez, EH Editores.

Aguayo Cobo, A. [2002]. «El palacio como espejo del caballero humanista: el palacio de don Pedro Benavente Cabeza de Vaca, en Jerez" en Bernat Vistarini, A. y Cull, J. T. (Eds). Los días del Alción. Emblemas, Literatura y Arte del Siglo de Oro. Palma de Mallorca, José J. de Olalleta, 7-26.

Chasseneuz, B. de [1529]. Catalogus Gloriae Mundi, Lion, Dionysium de Harsy.

Checa Cremades, F. [1987]. Carlos Vy la imagen del héroe en el Renacimiento, Madrid, Taurus.

Checa Cremades, F. [2006]. Pintura y escultura del Renacimiento en España. 1450-1600, Madrid, Cátedra.

Cuevas, J. de las [1964]. La canción de Barahona Padilla, Jerez, CEHJ.

Escobar Fernández, B. [2020]. «De ornato e antigua memoria de esta ciudad. Aportaciones para el estudio del urbanismo jerezano en el quinientos», Revista de Historia de Jerez, 23, 69-84.

Esteve Guerrero, M. [1933]. Jerez de la Frontera. Guía oficial de arte, Jerez, Jerez Gráfico.

Hernández Correa, V., y otros [2013]. «De La Palma a Sevilla: Varia biobibliográfica de Bernardino de Riberol y su libro Alabanza de la Pobreza (1556)", Cartas diferentes. Revista canaria de patrimonio documental, 9, 259-294.

Iglesia, J. de la [2001]. «Las Artes Liberales en la Biblioteca Real del Escorial, dos antecedentes iconográficos", en Campos Y Fernández de Sevilla, F. J. (Coord.): El Monasterio del Escorial y la pintura. San Lorenzo del Escorial, Universidad María Cristina, 1 19-164.

Lleó Cañal, V. [2012]. Nueva Roma. Mitología y humanismo en el Renacimiento sevillano, Madrid, CEEH.

Lleó Cañal, V. [2017]. La casa de Pilatos. Biografía de un palacio sevillano. Sevilla, Editorial Universidad de Sevilla.

11. El jerezano Palacio de Riquelme cuenta en su fachada con un conjunto de Uomini Illustri que podría leerse como ancestros míticos del comitente. Véase Moreno (2019: 123) 
López Campuzano, J. [1992]. «La ornamentación escultórica del patio de la casa-palacio de Camporreal en Jerez de la Frontera», Archivo Español de Arte, 65 (257), 102-110. $<$ https://doi.org/10.3989/aearte>

López Campuzano, J. [1995]. Humanismo en la arquitectura del siglo XVI de Jerez de la Frontera, Sevilla, Caja San Fernando.

López-Peláez Casellas, M. P. [2004]. «'Consonancias y armonías fingidas': la vinculación entre la música y la lisonja en las representaciones artísticas», Espacio, tiempo y forma, VII, 17, 81-96.

Marías Franco, F. [1989]. El largo siglo XVI. Madrid, Taurus.

Marín Fidalgo, A. [1990]. El Alcázar de Sevilla bajo los Austrias. Tomo I, Sevilla, Ediciones Guadalquivir.

Martín Rodríguez, F. G. [1995]. Santa Cruz de La Palma: la ciudad renacentista. Santa Cruz de Tenerife, Cepsa.

Mayo Escudero, J. [2001]. Protocolo primitivo y de fundación de la Cartuja de Santa María de la Defensión. Jerez de la Frontera. (Cádiz). Salzburgo, Analecta Cartusiana.

Mingorance Ruiz, J. A. [2014]. La colonia extranjera en Jerez a finales de la Edad Media. Ediciones Presea, Jerez.

Mingorance Ruíz, J. A. [2017]. «Bases económicas de la aristocracia bajomedieval: el veinticuatro jerezano Pedro Benavente Cabeza de Vaca», Archivo Hispalense, 303-305 (201), t. C, 97-129.

Montesinos Castañeda, M. [2019]. La visualidad de las virtudes cardinales. Valencia, Universidad de Valencia. http://dx.doi.org/10.7203/imago.11.15428

Moreno Arana, J. A. [2017a]. «Relaciones epistolares entre anticuarios jerezanos y sevillanos del siglo XVI», Archivo Hispalense, 303-305, t. C, 157- 183.

Moreno Arana, J. A. [2017b]. «Illustrium Imagines (Roma, 1517) de Andrea Fulvio, fuente de la decoración escultórica de la fachada del palacio de Riquelme de Jerez de la Frontera (1542-1543)", Boletín de Arte, 38, 211-214.

Moreno Arana, J. A. [2019]. Un episodio cultural de Jerez de la Frontera en el siglo XVI, Madrid, Bubok.

Parada Y Barreto, D. I. [1875]. Hombres ilustres de la ciudad de Jerez de la Frontera, Jerez, Imprenta del Guadalete.

Pons Fuster, F. [2003]. Erasmistas, mecenas y humanistas en la cultura valenciana de la primera mitad del siglo XVI, Valencia, Institución Alfonso el Magnánimo.

Riberol, B. de [2006]. Libro contra la ambición y codicia desordenada de aqueste tiempo: llamado alabanza de la pobreza, Edición de Manuel de Paz Sánchez, La Laguna: Centro de la Cultura Popular Canaria.

Ríos Martínez, E. de los [1991]. "Arquitectura civil jerezana en el siglo XVI», Páginas, 6, 52-66.

Ríos Martínez, E. de los [1999]. «La Historia del Arte en Jerez desde la Edad Media hasta el siglo XVII», en CARO CANCELA, Diego (coord.), Historia de Jerez de la Frontera, Cádiz, Diputación Provincial de Cádiz. t. III, 11-102.

Romero Bejarano, M. [2009]. De los orígenes a Pilar Sánchez. Breve historia de Jerez, Jerez, Ediciones Remedios 9.

Romero Bejarano, M. [2014]. Maestros y obras de ascendencia portuguesa en el Tardogótico de la Baja Andalucía. Tesis doctoral inédita, Universidad de Sevilla. 
Romero Bejarano, M. [2016]. «Notas sobre la construcción del palacio Ponce de León», en Pérez Mulet, F. (Dir.) y Aroca Vicenti, F. (Coord.), Nuevas aportaciones a la Historia del Arte en Jerez de la Frontera y su entorno. Cádiz, Editorial UCA, 157-173.

Ruiz Pilares, E. [2020]. La sociedad política en Jerez de la Frontera a finales de la Edad Media, Cádiz, Editorial UCA.

Saavedra Fajardo, D. de [1655]. Empresas políticas. Amberes, Jerónimo y Juan Bautista Verdussen.

Sánchez Saus, R. [1996]. Linajes medievales de Jerez de la Frontera. Sevilla, Ediciones Guadalquivir.

Sancho De Sopranis, H. [1925]. «Papeles viejos. Cartas dirigidas al Comendador jerezano Pedro de Benavente, por varios obispos, por los Duques de Gandía y Calabria, Marqueses de Tarifa y la Cerda y otros personajes", en Revista del Ateneo de Jerez, 6, enero, 165-167.

Sancho De Sopranis, H. [1947]. "Una obra desconocida del maestro Andrés de Ribera: La capilla del Comendador Pedro de Benavente Cabeza de Vaca en la real Iglesia de San Lucas", Ayer, Jerez, 13 de abril de 1947, 3-4.

Sancho De Sopranis, H. [1953]. "Cádiz y la piratería turco-berberisca en el siglo XVI», Archivo del Instituto de Estudios Africanos, 26, 7-77.

Sancho De Sopranis, H. [1959]. Establecimientos docentes de Jerez de la Frontera en la primera mitad del siglo XVI, Jerez, Centro de Estudios Históricos Jerezanos, 1959.

Villalón, C. de [1982]. El crotalón. Edición de Asunción Rallo, Madrid, Cátedra.

Viña Brito, A. [2003]. «Los Benavente Cabeza de Vaca, vecinos de Jerez y grandes propietarios en La Palma (Canarias) ", en Andalucía Medieval. Actas del III Congreso de Historia de Andalucía, Córdoba, Cajasur, 2003, vol. II, 323-336. 